such studies of pathological variants (Nature New Biology, 230, $261 ; 1971$ ), and now Greer has contributed two new investigations of different types of structural aberration. To anybody except the young, the excessively blasé and the punch-drunk, they compel awe and fascination.

In the first article (J. Mol. Biol., 59, $99 ; 1971$ ), Greer uses the difference Fourier method to study the structural effects of two different substitutions at a single position in the $\beta$-chain. Asn102 is conserved in all known animal $\beta$-chain sequences, and may therefore be supposed to admit of little genetic tinkering. In haemoglobin Kansas, however, it is replaced by threonine, which causes the loss of cooperative function, and a decrease in oxygen affinity at physiological $\mathrm{pH}$; in haemoglobin Richmond it is replaced by lysine, without any clinical penalty.

The difference electron density map of deoxygenated Kansas shows a disturbance near the $\beta$-haem group, for the threonine causes crowding at a vinyl and methyl side chain. The haem is displaced, and with it the helix to which it is linked by way of the histidine iron ligand. This has other consequences, including a distortion at the interface of the $\alpha_{1}$ and $\beta_{1}$ chains which affects even the $\alpha$-chain structure at various points, including the haem surrounds. The threonine cannot fulfil one of the functions of the asparagine, of hydrogen bonding to an $\alpha$-chain aspartate, and appears instead to form an intra- $\beta$-chain bond. In haemoglobin Richmond, the distortion of the structure under the influence of the substitution is much less, and the lysine is even able to bond to the $\alpha$-chain aspartate. A consequence of one of the new contacts is to displace another arginine, which normally shows a prominent interaction with an $\alpha$-chain tyrosine. Possibly for this reason the Richmond molecule dissociates much more readily than normal haemoglobin into dimers. In haemoglobin Kansas, in which an important saltbridge is absent, and the structure is generally distorted, this effect is still more pronounced.

Greer's second article (ibid., 107) concerns itself with two haemoglobin $\mathbf{M}$ forms, Hyde Park and Iwate. The M variants are characterized by substitutions for haem-linked histidines, the corresponding haem groups being then inert with respect to oxygen, and normally in the ferric form. Haemoglobin Iwate has an $\alpha$-chain substitution, and Hyde Park a $\beta$-chain, histidine being in both cases replaced by tyrosine. The chemistry of these forms shows many peculiarities-in one of them, for example, the isomorphous replacement by a mercurial occurs at the wrong thiol. The Hyde Park variant moreover has a tendency to shed its $\alpha$-haem groups and in a proportion of the molecules in the crystal of the fully reduced pigment (and no doubt in solution) the haem is missing and its cavity is collapsed. The disturbance is localized, however, and is not transmitted to the rest of the molecule. Neither the aberrant tyrosine nor the distal histidine in this molecule approaches the haem.

In the $\alpha$-chain Iwate variant the $\alpha$-haem iron is evidently linked to the tyrosine and the normal distal histidine. The most striking feature of the structure in both the fully ferric and the $\beta$ deoxy-forms is that it is fixed in the deoxy-configuration, in spite of welldefined changes in the $\beta$-chain when its haem is liganded. This rationalizes the striking difference between the two $\mathbf{M}$ variants, Hyde Park having both normal oxygen affinity in its functional haems and a Bohr effect, and Iwate a low oxygen affinity and no Bohr effect. Evidently the tyrosine-iron bond prevents the normal steric transition to a state favouring the transition to the highaffinity quaternary structure, which, one may infer, originates in the $\alpha$-chains. Molecular pathology aside, the particular value of these studies. especially when details can be seen at higher resolution, will be to reveal the nature of the intermediate states between the fully reduced and fully oxygenated forms, which could not otherwise be observed by crystallography.

\section{STRATIGRAPHY \\ Fixing a Boundary}

from a Correspondent

IT cannot be often that the Red Army is responsible for a geological article. In August 1968 the International Commission on Stratigraphy met in Prague and was about to consider a proposal that the boundary between the Silurian and the Devonian should be fixed at the base of the Monograptus uniformis Zone, which is appreciably below the traditional base of the Devonian in Russia and Czechoslovakia, but unfortunately well above its base in Britain. The practical consequence of this in the classic area of the Welsh Borderland would be to transfer the lowest Devonian strata as originally defined by Murchison to the Silurian system. The support for the proposal suggests that it would have been accepted had the work of the commission not been interrupted. Because of the invasion, however, the matter is still open to debate. Westoll, Shirley, Dinely and Ball have recently taken advantage of this respite to argue (J. Geol. Soc., 127, 286; 1971) that the traditional position of the boundary between the two systems should be retained.

This may seem a rather arid discussion of interest solely to specialists. In

\title{
Marine Bands and Tonsteins revealed in Derbyshire
}

THE Westphalian Coal Measures are remarkable for the continuity and persistence of certain rock types, especially the marine bands which have characteristic fossil fauna resulting from relatively short lived but widespread marine invasions of the coal delta. These bands have long been accepted as reliable stratigraphic markers on which to subdivide and to correlate the coal measures of the British Isles and Europe. The thin, curious, kaolinitic bands called tonsteins discovered more recently in the coalfields of Western Europe have provided welcome additional markers for correlation purposes.

Tonsteins were first found in North Staffordshire in 1961 and discoveries in other British coalfields have followed, particularly at one horizon below the equivalent of the Edmondia Marine Band. They are usually only a few centimetres thick, yet some of them are traceable over hundreds of square miles and, as in the case of some marine bands, a few can be traced throughout the coalfields of Western Europe. Their origin is problematical and probably varied; the volcanic ash idea is attractive in terms of widespread persistence but it is also held that they are the result of special soil forming processes.

In the forthcoming issue of Nature Physical Science, M. A. Calver, who has been associated with many discoveries of new marine bands in British coalfields, is joined by B. C. Worssam and $\mathrm{G}$. Jago to demonstrate again that continuous core drilling coupled with examination can still reveal hitherto unproved marine bands and tonsteins. A series of boreholes drilled in the Pottery Clays of the South Derbyshire Coalfield during 1970 on behalf of the Institute of Geological Sciences and the National Coal Board have added considerably to the knowledge of the stratigraphy of these coal measures. Above the Overseal Marine Band Calver et al. have recorded the presence of the marine bands equivalent to the Top, Shafton and Edmondia Bands of the East Pennine Coalfields and they have also recorded a tonstein which occurs a little below the last of these bands at about the position of the SubHigh Main tonstein; another new tonstein is located between the Top and Shafton marine horizons. The elusive marine bands between the Overseal and underlying Two Foot have also been found and correlated. 
fact, it arises from a more important philosophical question-how geological time should be measured. When stratigraphy was in its infancy, it was natural to fix on spectacular events the effects of which were readily apparent and to use these for dividing the geological record.

More recent ideas on the philosophy of stratigraphy, however, suggest that time is a continuum, and that stratigraphic boundaries are merely arbitrary divisions, much as the hours of the day are arbitrary. Once a boundary is agreed, and defined by a type section, stratigraphers can get on with their real business-correlation. From this it follows that type sections should be chosen in areas where the rocks have all the features useful in correlation-good varied faunas (preferably marine) and as few obvious breaks as possible. This means that the traditional type sections of the Silurian/Devonian boundary in the Welsh Borderland just will not do-not only are half the rocks continental, but the famous Ludlow Bone Bed represents a marked time break. A very suitable type areat seems to bc the Barrandium Syncline near Prague, which was protected from the major movements of the Earth which disturbed north-west Europe in early Devonian times and where the graptolites, all-important in correlation. were not forced to extinction.

Geologists are agreed that the new proposal presents British stratigraphers with some difficulties, as Westoll and his colleagues point out. They suggest that the boundary should be fixed at another graptolite zone rather lower in the succession, marked by Monograptus ultimus, which would give a boundary very close to the position of the Ludlow Bone Bed.

Not all their British colleagues take this view; there is considerable British support for the new proposal. It will be interesting to see whether Westoll. Shirley, Dinely and Ball are fighting a rearguard action or starting a successful counter attack.

\section{OLFACTION}

\section{Smells Leff and Right}

from our Membrane Correspondent

IT has been reported that compounds, which differ only in their stereochemical configuration about one carbon atom, have distinguishably different odours. It is possible, however, that the difference in smell between these enantiomers can be attributed to that bugbear of olfactory research, the presence of unidentified impurities.

Earlier this year Leitereg et al. (Nature, 230, 455; 1971) presented good evidence that the optical isomers $(+)$ and (-)-carvones, prepared from both natural and synthetic sources, have different odours-caraway and spearmint respectively-but these authors still paid lip service to the possibility that the odour difference was caused by impurities. This possibility has now been convincingly eliminated in some recent work reported by Russell and Hills (Science, 172, 1043: 1971) and by Friedman and Miller (ibid., 1044).

Russell and Hills investigated five different enantiomeric pairs of compounds- $(+)$ - and $(-)$-carvones and four derivatives of each of these. The actual samples used for odour evaluation were purified fractions which were collected after successive passages through two different gas-liquid chromatography (GLC) columns. In each case there was a highly significant difference in odour quality. Using GLC and a variety of synthetic pathways, Friedman and Miller investigated eight different enantiomeric pairs which had distinct odour differences. All but one (amphetamine) of the pairs were terpenoid compounds and these included the carvones and also (+)- and (-)limonenes; the last two had the odour of oranges and lemons respectively-as in the case of the carvones this is a far from subtle difference in odour. Friedman and Miller paid particular attention to the carvones; they resolved a racemic mixture, synthesized them by two different routes and also subjected them to a cycle of reactions which interconverted the + form to the form and back again. The final products of all these manipulations were subjected to odour evaluation. The odours of the + forms were indistinguishable from each other as were the odours of the - forms, but the + and - pairs always had a significant difference in odour.

The postulated impurities now come to have unbelievable properties. There would have to be a different pair of impurities for many of the enantiomeric pairs studied, and in each case these impurities must survive both the GLC purification and the wide variety of chemical manipulations. Furthermore, just the same impurities would have to be present in both natural and synthetic compounds.

The vibrational and rotational modes of enantiomers are identical so that the now clearly established fact that enantiomers can have different odours spells death to any theory of olfaction which looks for correlations between odour quality and infrared spectra. Furthermore, other theories are now faced with the task of explaining why some enantiomeric pairs have different odours and other pairs have identical odours.

\section{Some Pulsars May Emit Thermal X-rays}

THE view that pulsars may consist of a superfluid core of neutrons surrounded by a rigid crust, as suggested by Baym, Pethick, Pines and Ruderman, is examined by George Greenstein of Princeton University Observatory in next Monday's Nature Physical Science. So far the attraction of the model of Baym and his colleagues has been that it accounts in a neat way for some of the irregularities in the behaviour of pulsars, interpreted in terms of starquakes occurring in the rigid crust. In this model the slowdown of the spin of the pulsar is accompanied by frictional heat as a result of slippage between the crust and the core.

Greenstein has evaluated the magnitude of this heating, which is on top of the temperature expected for pulsars on the basis of cooling theory, so that the temperatures which he obtains from an examination of the slowdown of pulsars can be considered as lower limits to pulsar temperatures.

It will not come as a surprise that the two pulsars for which the frictional heating process seems significant are the two fast pulsars, in the Crab Nebula and in Vela. For both these objects Greenstein finds temperatures caused by frictional heating arising between the rigid crust and neutron superfluid of $10^{6} \mathrm{~K}$. He suggests therefore that thermal X-ray emission ought to be detectable from these two objects---he expects them both to have X-ray fluxes of the order of $3 \times 10^{-27} \mathrm{erg} \mathrm{cm}^{-2}$ $\mathrm{s}^{-1} \mathrm{~Hz}^{-1}$.

It may also be possible to detect the thermal X-ray flux of $1 \times 10^{-28} \mathrm{erg} \mathrm{cm}^{-2}$ $\mathrm{s}^{-1} \mathrm{~Hz}^{-1}$ that is expected from what is thought to be the closest pulsar, CP 0950. Another possibility is that pulsars the orientation of which is such that their pulsations are not detectable at the Earth may be discovered by their thermal X-radiation.

But for other pulsars the expected thermal X-ray emission is appreciably weaker-1 $1 \times 10^{-30} \mathrm{erg} \mathrm{cm}^{-2} \mathrm{~s}^{-1} \mathrm{~Hz}^{-1}$ for HP 1508 and $3 \times 10^{-29} \mathrm{erg} \mathrm{cm}^{-2} \mathrm{~s}^{-1} \mathrm{~Hz}^{-1}$ for CP 1133. For these two objects the expected associated visual magnitudes are 32 and 27 respectively, far beyond the capabilities of the best optical telescopes.

Greenstein also reports that the heating at the inner boundary of the core takes place in a thin shell that can be a kilometre or so, or less, in thickness. $\mathrm{He}$ also points out that his equations indicate that fluctuations in the temperatures of pulsars are mirrored by corresponding fluctuations in the periodicity of the pulses, so that the regularity of pulsars implies that their temperatures are also kept amazingly constant. 